\title{
A Segurança Nacional No Regime Militarista
}

The National Security In The Militarist Regime

Gilvan Charles Cerqueira de Araújo*

\section{RESUMO}

Este artigo tem como foco de análise a segurança nacional durante o regime da Ditadura Militar no Brasil. Como temas correlatos há a questão econômica que permeou este período, conjuntamente ao discurso integracionista, que trazia consigo elementos para o aporte territorial deste direcionamento do governo à época em questão, de modo a entrelaçar as diferentes formas de cruzar as informações, dados e discussões presentes na questão da segurança nacional brasileira.

PALAVRAS-CHAVE: Segurança Nacional; Integração Nacional; Regime Militar.

\begin{abstract}
:
This paper focuses on national security analysis during the regime of the Military Dictatorship in Brazil. As related themes there is the economic question that permeated this period, concomitant with a integrationist discourse, which brought with it elements for the territorial contribution of this direction of government at the time in question, involving the different ways of crossing the information, data and present discussions on the issue of Brazilian national security.
\end{abstract}

KEYWORDS: National Security; National Integration; Military Regime.

\section{INTRODUÇÃO}

O presente artigo é uma versão adaptada de parte da tese de doutorado em Geografia, defendida em 2016 na Universidade Estadual Paulista - UNESP, campus de Rio ClarolSP. O tema central tratado aqui concentra-se na questão da segurança nacional durante o regime militar brasileiro, tendo como ponto de partida ideias como a de desenvolvimento, gestão de fronteiras e o papel do Estado brasileiro como balizador e fomentador de uma visão centralizada do poder nacional.

Autores do pensamento geográfico foram trazidos para o debate, assim como os temas e demais contribuições que corroboram para os argumentos apresentados como, por exemplo, a questão do papel da economia o discurso militar, o fortalecimento da ufania territorial como aporte simbólico para os anseios governamentais e estofo considerável da ideia integracionista, perene e permanente durante os aos do regime militar no Brasil.

$\mathrm{O}$ artigo está dividido em dois grandes tópicos que se complementam na temática e desenvolvimento da argumentação proposta. Num primeiro momento há a contextualização 
ARAÚJO, G. C. C.

política envolvendo a questão da segurança e integração nacional do Estado nacional brasileiro. No segundo momento há a questão das estratégias militares inseridas nas proposta de pensamento e intervenção a respeito da integração nacional e da segurança do território brasileiro, especialmente no período da ditadura militar, em seus anos mais duros de governo.

\section{A segurança nacional, contextualização político-econômica}

A preocupação com a segurança e integração nacional do território brasileiro é algo perene em nossa história recente, tendo assistido sua maior expansão durante os anos de expansão do poder governamental dos militares, apoiado pelos elevados coeficientes de crescimento econômico atingidos pelas políticas estatais de gestão da economia nacional, estratégias e restados que ficaram conhecidos como o milagre brasileiro.

Se do ponto de vista econômico houve o "milagre brasileiro" como principal aporte de justificativa de poder estatal dos militares, por outro lado, de forma concomitante, uma ideologia geopolítica da segurança nacional dominou todo o corpo discursivo e interventivo dos órgãos estatais na ditadura.

Os planos e planejamentos alinhavavam a um só tempo a propaganda da unidade e integração nacional à necessidade de domínio, controle e regulação das fronteiras do território, a essência da doutrina ideológica da segurança nacional, definido e instaurado pelo Decreto de Lei $\mathrm{n}^{\circ} 314$ de 1967:

Art. $3^{\circ} \mathrm{A}$ segurança nacional compreende, essencialmente, medidas destinadas à preservação da segurança externa e interna, inclusive a prevenção e repressão da guerra psicológica adversa e da guerra revolucionária ou subversiva. $\S 1^{\circ}$ A segurança interna, integrada na segurança nacional, diz respeito às ameaças ou pressões antagônicas, de qualquer origem, forma ou natureza, que se manifestem ou produzam efeito no âmbito interno do país. $\S 2^{\circ}$ A guerra psicológica adversa é o emprêgo da propaganda, da contrapropaganda e de ações nos campos político, econômico, psicossocial e militar, com a finalidade de influenciar ou provocar opiniões, emoções, atitudes e comportamentos de grupos estrangeiros, inimigos, neutros ou amigos, contra a consecução dos objetivos nacionais. $\S 3^{\circ} \mathrm{A}$ guerra revolucionária é o conflito interno, geralmente inspirado em uma ideologia ou auxiliado do exterior, que visa à conquista subversiva do poder pelo contrôle progressivo da Nação. (BRASIL, 1967, p. 1). 
E, anterior a este decreto houve a criação do SNI, servindo como uma prévia do que viria a se concretizar como toda uma forma de organização do Estado poucos anos depois de sua fundação. Para Moraes (2011), esta doutrina, juntamente com a carga da ufania edênica e da propaganda do orgulho telúrico, formatou todo o olhar dos militares sobre a população e o território nacional. A segurança nacional servia como pano de fundo para os objetivos de implantação das políticas regionais de desenvolvimento, transformando em "inimigo interno" o atraso técnico (e cultural, na visão progressista), as desigualdades regionais e, também, aqueles que se colocassem como dissidentes desta premissa geopolítica:

[...] o golpe militar de 1964 representou um ponto de inflexão na tendência observada de incorporar o tema da nação (e da cidadania) na formulação dos projetos nacionais. $\mathrm{O}$ governo ditatorial repôs com ênfase a ótica geopolítica tradicional na concepção do país e do desenho de seu futuro. Não só a visão territorialista foi retomada no período como a máxima da tutela do povo em nome da integridade do espaço foi fortemente resgatada pela Doutrina de Segurança Nacional implantada pelos militares, a qual identificava setores da população com um possível "inimigo interno" que colocava em risco a soberania do país. a meta da integração nacional explicitada pelo regime militar completava a identificação do país com seu território, reafirmando os objetivos do desenvolvimento econômico e da ultrapassagem das desigualdades regionais. (MORAES, 2011, p. 94-95).

E, mais do que declarar guerra a estes "inimigos", havia a necessidade de transfigurar a intervenção desmedida do Estado na forma um suposto fortalecimento da democracia para o povo brasileiro: "A argumentação sobre a necessidade de conciliar segurança com desenvolvimento econômico para se alcançar, através dela, uma hipotética estabilidade política era, também, calcada no sistema de idéias e valores sobre uma supositícia intenção democratizante da ditadura." (REZENDE, 2013, p.103). Esta visão dual entre a garantia da segurança nacional com o desenvolvimento econômico e a democracia do país pode ser constatada nas palavras do ex-presidente Garrastazu Médici:

Apresentarei à Nação, oportunamente, um plano econômico e administrativo, resguardando basicamente os resultados já obtidos pela Revolução, fixando as novas metas de incremento da produção e de expansão do mercado, tendo em vista a prioridade dos setores da educação, da saúde e da alimentação, o atendimento das regiões menos desenvolvidas, a estabilidade monetária, a correção dos desequilíbrios regionais de renda,, a redução das desigualdades na distribuição das rendas individuais, - os salários justos e a participação dos trabalhadores nos benefícios do 
ARAÚJO, G. C. C.

desenvolvimento e, tem assim, os critérios das reformas institucionais. (MÉDICI, 1969, p. 13).

Para sermos mais específicos, mesmo com todo o poder policial, de censura e as cifras econômicas para suporte político, era necessário que os militares, ao menos figurativamente, fizessem emanar a democracia como ponto primordial de suas ações e interesses. Desta forma, doutrinas como a de segurança nacional, juntamente com os esforços organizacionais e institucionais da integridade e unidade da nação, se tornariam ainda mais expressivos e sustentáveis pelo regime ditatorial:

Desse modo, ao término do meu período administrativo, espero deixar definitivamente instaurada a democracia em nosso país e, bem assim, fixadas as bases do nosso desenvolvimento econômico e social. Advirto que essa não poderá ser obra exclusiva da administração pública, e sim, uma tarefa global da Nação, exigindo a colaboração dos brasileiros de todas as classes e regiões. Democracia e desenvolvimento não se resumem em iniciativas governamentais: são atos de vontade coletiva que cabe ao Governo coordenar e transformar em autênticos e efetivos objetivos nacionais. (MÉDICI, 1969, p. 11).

Rezende (2013) a posição de Médici: “Os militares no poder insistiam em que os órgãos da democracia representativa estariam preservados à medida que o Congresso e os partidos estivessem submetidos aos ditames do executivo." A corrosão dos órgãos representativos da democracia na visão dos militares prejudicaria sua comunicação com a população, à qual destinava seu "pacto" em prol do crescimento da nação: "Este último era, então, o órgão máximo de representação dos interesses do povo; o que vai culminar, nos anos posteriores, com a dispensa de instituições de representação, pois o executivo estabeleceria diretamente, segundo os condutores da ditadura, o contato com todos os setores sociais." (REZENDE, 2013, p. 80).

Giannasi (2011) considera a doutrina da segurança nacional como uma proposta de alteração do próprio corpo estatal brasileiro, em continuidade à objetivação do Estado em seu território, como corpofiricação, assim como nos governos anteriores à ditadura militar, já que era preciso alterar suas modulações fundamentais para o sucesso desta ideologia: "O objetivo da Doutrina era reorganizar o Estado brasileiro em outros moldes. [...] aos direitos de participação política da cidadania em geral.” (GIANNASI, 2011, p. 117).

Rezende (2013) é mais agudo em sua crítica à doutrina, classificando-a como sendo um processo de "saneamento moral", a partir do qual os militares poderiam interferir a seu bel-prazer nos direitos dos cidadãos, em ações diretas (como a censura), ou indiretas, em 
ARAÚJO, G. C. C.

políticas de subjetivação ufanistas, de modo a garantir seus interesses de controle governamental:

\begin{abstract}
O saneamento moral era um dos elementos definidores do suposto ideário de democracia da ditadura. O Ministro da Justiça dizia-se incumbido de formar os homens democráticos nos moldes do novo regime; o que significava banir da mentalidade dos brasileiros todo e qualquer espírito de oposição e/ou contestação. Os pronunciamentos dos militares e civis que conduziam o regime iam sempre no sentido de estabelecer um conjunto de normas e idéias que criassem atitudes favoráveis ao estado de coisas vigentes. O saneamento moral era uma espécie de valor objetivo e subjetivo ao mesmo tempo. Objetivo no sentido de que o regime se debatia para formar um juízo favorável sobre ele, as Forças Armadas e as instituições (família, Estado, escola, etc.) que a ditadura se dizia incumbida de proteger. Este empenho devia, então, culminar em aceitação e internalização desses valores pelos indivíduos, grupos e instituições sociais. A criação de valores sociais positivos e/ou favoráveis ao regime visava fundamentalmente alcançar adesão dentro e fora do grupo de poder. (REZENDE, 2013, p. 82).
\end{abstract}

Este saneamento moral mencionado pelo autor pode ser observado no decurso da efetivação dos atos institucionais do período ditatorial. Cada ato, a seu modo, estabelecia os parâmetros de ação do governo após o golpe de 1964, desde a dissolução do Congresso Nacional até a afirmação das eleições indiretas para o poder executivo e limitação dos direitos civis e sociais, estes últimos fortalecendo o poder coercitivo do Estado.

Quadro-1 Os Atos Institucionais

\begin{tabular}{|c|c|c|}
\hline $\begin{array}{c}\text { Ato } \\
\text { Institucional }\end{array}$ & Ano & Conteúdo \\
\hline A I 1 & 9 de abril de 1964. & $\begin{array}{l}\text { Modifica a Constituição do Brasil de } 1946 \\
\text { quanto à eleição, ao mandato e aos poderes do } \\
\text { Presidente da República; confere aos } \\
\text { Comandantes-em-chefe das Forças Armadas o } \\
\text { poder de suspender direitos políticos e cassar } \\
\text { mandatos legislativos, excluída a apreciação } \\
\text { judicial desses atos; e dá outras providências. }\end{array}$ \\
\hline A I 2 & $\frac{27 \text { de outubro de }}{\underline{1965 .}}$ & $\begin{array}{l}\text { Modifica a Constituição do Brasil de } 1946 \\
\text { quanto ao processo legislativo, às eleições, aos } \\
\text { poderes do Presidente da República, à } \\
\text { organização dos três Poderes; suspende } \\
\text { garantias de vitaliciedade, inamovibilidade, } \\
\text { estabilidade e a de exercício em funções por } \\
\text { tempo certo; exclui da apreciação judicial atos } \\
\text { praticados de acordo com suas normas e Atos }\end{array}$ \\
\hline
\end{tabular}




\begin{tabular}{|c|c|l|}
\hline & & $\begin{array}{l}\text { Complementares decorrentes; e dá outras } \\
\text { providências. }\end{array}$ \\
\hline A I 3 & $\underline{5 \text { de fevereiro de }}$ & $\begin{array}{l}\text { Dispõe sobre eleições indiretas nacionais, } \\
\text { estaduais e municipais; permite que Senadores } \\
\text { e Deputados Federais ou Estaduais, com prévia } \\
\text { licença, exerçam o cargo de Prefeito de capital } \\
\text { de Estado; exclui da apreciação judicial atos } \\
\text { praticados de acordo com suas normas e Atos } \\
\text { Complementares decorrentes. }\end{array}$ \\
\hline A I 4 & $\underline{1966 .}$ & $\begin{array}{l}\text { Convoca o Congresso Nacional para discussão, } \\
\text { votação e promulgação do Projeto de } \\
\text { Constituição apresentado pelo Presidente da } \\
\text { República e dá outras providências. }\end{array}$ \\
\hline$\underline{1966 .}$ & $\begin{array}{l}\text { Suspende a garantia do habeas corpus para } \\
\text { determinados crimes; dispõe sobre os poderes } \\
\text { do Presidente da República de decretar: estado } \\
\text { de sítio, nos casos previstos na Constituição } \\
\text { Federal de 1967; intervenção federal, sem os } \\
\text { limites constitucionais; suspensão de direitos } \\
\text { políticos e restrição ao exercício de qualquer } \\
\text { direito público ou privado; cassação de } \\
\text { mandatos eletivos; recesso do Congresso } \\
\text { Nacional, das Assembléias Legislativas e das } \\
\text { Câmaras de Vereadores; exclui da apreciação } \\
\text { judicial atos praticados de acordo com suas } \\
\text { normas e Atos Complementares decorrentes; e } \\
\text { dá outras providências. }\end{array}$ \\
\hline$\underline{13 \text { de dezembro de }}$
\end{tabular}

Fonte: http://www4.planalto.gov.br/legislacao

Após a promulgação do Ato Institucional n5, ainda houve um complemento legal para a garantia da segurança nacional pelo governo, por meio da Emenda Constitucional de 1969, a qual instituía e regulava a política de segurança nacional, apontado diretrizes correspondentes aos objetivos geopolíticos dos militares:

Art. 89. Ao Conselho de Segurança Nacional compete:

I - estabelecer os objetivos nacionais permanentes e as bases para a política nacional;

II - estudar, no âmbito interno e externo, os assuntos que interessem à segurança nacional;

III - indicar as áreas indispensáveis à segurança nacional e os municípios considerados de seu interêsse;

IV - dar, em relação às áreas indispensáveis à segurança nacional, assentimento prévio para: 
ARAÚJO, G. C. C.

a) concessão de terras, abertura de vias de transporte e instalação de meios de comunicação;

b) construção de pontes, estradas internacionais e campos de pouso; e

c) estabelecimento ou exploração de indústrias que interessem à segurança nacional;

$\mathrm{V}$ - modificar ou cassar as concessões ou autorizações mencionadas no item anterior; e

VI - conceder licença para o funcionamento de órgãos ou representações de entidades sindicais estrangeiras, bem como autorizar a filiação das nacionais a essas entidades.

Parágrafo único. A lei indicará os municípios de interêsse da segurança nacional e as áreas a esta indispensáveis, cuja utilização regulará, sendo assegurada, nas indústrias nelas situadas, predominância de capitais e trabalhadores brasileiros. (BRASIL, 1969, p. 6).

Com esta base legal estabelecida nos anos de 1960, na década seguinte, e com a ajuda dos números da economia, os governos militares continuaram sua caminhada rumo ao fortalecimento de seu discurso sobre um Estado de Exceção, fundamentado na segurança nacional como aporte político de suas ações em diferentes esferas do país:

Os instrumentos excepcionais de que o Governo se acha armado para manutenção da atmosfera de segurança e de ordem, fundamental para o próprio desenvolvimento econômico-social do país, sem pausas de estagnação nem, muito menos, retrocessos sempre perigosos, almejo vê-los não tanto em exercício duradouro ou freqüente, antes como potencial de ação repressiva ou de contenção mais enérgica e, assim mesmo, até que sejam superados pela imaginação política criadora, capaz de instituir, quando for oportuno, salvaguardas eficazes e remédios prontos e realmente eficientes dentro do contexto constitucional». (GEISEL, 1974, p. 120).

Vlach (2003) propõe que a segurança nacional, permeada pela idéia do desenvolvimento como seu provedor de justificativa essencial, seria uma das manifestações desta doutrina. De forma objetiva, estas ideações foram utilizadas pelo Estado, mesmo que isto custasse a limagem dos direitos civis vigentes. Para a autora, estas teorias, advindas da Escola Superior de Guerra, protagonistas no papel de difusores destas idéias, disseminadas pelos líderes do poder executivo da ditadura:

[...] o princípio número um da ESG explicita que a segurança nacional é função, antes de mais nada, "do potencial geral da nação", não se limitando ao seu potencial militar. Ao longo dos anos, essas reflexões levaram ao aparecimento de uma doutrina brasileira de segurança nacional. E o objetivo da ESG é o de formar as elites dirigentes civis e militares, preparando-as para a implantação dessa doutrina. (VLACH, 2003, p. 7). 
ARAÚJO, G. C. C.

Com exceção da abertura do final do regime militar feita por João Figueiredo, todos os demais chefes de Estado da ditadura adotaram, em menor ou maior grau, estes artífices legais para fundamentar a repressão do Estado perante a sociedade, o sistema político e a estrutura econômica brasileira.

Todo este substrato ideológico da segurança nacional foi utilizado como forma de resguardar os ditames democráticos os quais, mesmo completamente ruídos pelo amparo legal e subjacências jurídicas pós-golpe de 1964, eram defendidos em discurso pelos presidentes militares, como forma de buscar o apoio popular para o regime de exceção em curso:

A portentosa construção» do futuro de grandeza que desejamos e antevemos para a nossa Pátria, deverá realizar-se, necessariamente, no quadro de nosso regime democrático, obedecidas regras fundamentais da conduta política, tais como as do atendimento real às mais caras aspirações do povo em geral, da representatividade legítima da vontade popular e da rotatividade periódica dos executivos, através de uma estrutura partidária, de natureza plural, dentro dos moldes constitucionais. (GEISEL, 1974, p. 114).

Também houve a doutrina da segurança nacional com a permanência do discurso do já desgastado desenvolvimentismo das décadas passadas pelo ex-presidente Figueiredo, mesmo após a crise econômica mundial nos anos de 1970, e a derrocada do "milagre brasileiro". Em consonância com a já evidente derrota da estratégia econômica utilizada nos primeiros anos militares, Figueiredo (1979) ainda tentou garantir alguma sobrevida ao discurso nacionalista dos militares, por meio das mazelas sociais que afligiam o território nacional na década de 1980:

Reafirmo o propósito de fazer da cidade um chão e teto habitáveis. Não a troca da miséria pela promiscuidade. Não o câmbio de uma forma de pobreza por outra - tão mais cruel, porque mais próximos os bens da civilização. Reafirmo a minha determinação de garantir a cada trabalhador a remuneração justa em relação ao trabalho produzido, às suas necessidades como chefe de família e à harmonia entre os vários segmentos da sociedade. Recordando as imortais palavras do Santo Padre Leão XIII: «Do trabalho do operário nasce a grandeza das Nações». Reafirmo: cada brasileiro tem direito de receber do Estado os cuidados básicos com sua saúde, com a própria educação e a dos filhos; assistência médico-social na enfermidade, no desemprego e na velhice; habitabilidade nas casas; meios de transporte que não sacrifiquem, nas filas e nas conduções, o tempo destinado ao lazer e ao convívio. (FIGUEIREDO, 1979, p. 8). 
ARAÚJO, G. C. C.

Além da admissão das dificuldades econômicas, ocorreria a inevitável abertura política, cabendo a Figueiredo explanar ao povo brasileiro a restituição dos direitos civis anulados nos anos de maior dureza do regime militarista:

\begin{abstract}
O objetivo final que sempre nos moveu - a todos quantos nos engajamos nessa cruzada patriótica - consiste em preservar valores essenciais à nossa maneira de vida. Entre esses valores se conta o convívio ou regime democrático, cujo aperfeiçoamento é nossa constante preocupação. Tenho plena consciência de que o caminho percorrido, sob o signo da democracia, que desejo plena e atuante, foi marcado por conquistas cujo alcance é desnecessário encarecer. Tais foram o restabelecimento das franquias fundamentais, a restituição dos direitos políticos aos que deles se achavam privados, bem como a concessão da anistia reclamada para a pacificação da família brasileira. Possuo consciência, também, como já tenho assinalado, de que a liberdade, garantida no passado, pode já ter sido igual, porém não foi maior do que a liberdade hoje reinante no País. (FIGUEIREDO, 1984, p. 44).
\end{abstract}

Observa-se que, mesmo finalizando a ditadura em seu governo, Figueiredo (1984) não deixa passar em branco um dos pilares dos governos militares sustentados pelo forte discurso nacionalista e patriótico. Dois pontos destacam-se em seu discurso: a questão da defesa nacional e da integração nacional, ambas assentadas nos preceitos firmados pelos ditames do regime de exceção, seja na regulação dos direitos civis, ou na exploração dos números econômicos, tencionando seu uso apenas macroeconomicamente ou então no fortalecimento de fato das ações geopolíticas de controle fronteiriço e observância espacial das políticas estatais.

\title{
A DEFESA E INTEGRAÇÃO DO TERRITÓRIO NACIONAL
}

Neste contexto do crescimento, e da ideologia militarista dos presidentes no cenário ditatorial estabelecida, dois generais, Calos Meira Mattos e Golbery do Couto e Silva podem ser lembrados como sintetizadores desta visão sobre o Estado nacional brasileiro, de modo a não só elaborar como fomentar muitas das políticas públicas dos governantes militares durante sua passagem no poder executivo do Brasil.

Para Couto e Silva (1981b), a segurança nacional e, em meio a ela, toda a preocupação perene dos militares com a defesa e integração do território, estava atrelada ao desenvolvimento. Tais teorizações ganhavam ainda mais força pelo histórico de continuidade de um Estado de Bem-Estar vigente desde o governo getulista e, também, pela também reincidente menção aos recursos naturais em abundância para justificar a preocupação com a 
ARAÚJO, G. C. C.

defesa e integração nacional, bem como o e crescimento da economia e desenvolvimento do país:

À medida que se sacrifique o bem-estar, em proveito da segurança, canalizando recursos daquele para esta, o primeiro decresce, enquanto a segurança aumenta mais que proporcionalmente, a princípio; a partir de certo ponto, porém, sofre a curva acentuada inflexão, e os acréscimos, agora cada vez menores, acabarão por se anular de todo, quando se haja alcançado o que, teoricamente, corresponde ao máximo de segurança compatível com a limitação imposta pelos recursos disponíveis. Reduza-se, ainda mais, o bemestar, e a própria segurança se verá, agora, decrescida. Segurança e BemEstar e, em plano mais elevado, Segurança e Liberdade são dilemas decisivos com que sempre se viu defrontada a humanidade, nunca, porém, como hoje, em circunstâncias tão dramáticas e tão imperiosas. (COUTO E SILVA, 1981b, p. 370).

Para Meira Mattos, segurança nacional e desenvolvimento são indissociáveis, e em meio às duas noções estariam problemas históricos do Brasil, como a concentração de renda. Numa outra vertente, está mais voltada ao poder militar propriamente dito, há a defesa da base industrial ligada aos anseios modernizadores e progressistas, e também a estabilidade das instituições de coerção presentes ao longo da ditadura militar:

\begin{abstract}
Desenvolvimento e segurança são ligados por uma relação de mútua causalidade. De um lado, a verdadeira segurança pressupõe um processo de desenvolvimento, quer econômico, quer social. Econômico, porque o poder militar está também essencialmente condicionado à base industrial e tecnológica do País. Social, porque mesmo um desenvolvimento econômico satisfatório, se acompanhado de excessiva concentração de renda e crescente desnível social, gera tensões e lutas que impedem a boa prática das instituições e acabam comprometendo o próprio desenvolvimento econômico e a segurança do regime. De outro lado, o desenvolvimento econômico e social pressupõe um mínimo de segurança e estabilidade das instituições. E não só as instituições políticas que condicionam o nível de eficiência dos investimentos do Estado, mas também das instituições econômicas e jurídicas, que, garantindo a estabilidade dos contratos e o direito de propriedade, condicionam, de seu lado, o nível de investimentos privados. (MATTOS, 1975, p. 62).
\end{abstract}

O Estado, tanto para Meira Mattos (1975) como para Couto e Silva (1981a) deveria ser o ponto centrípeto da coesão, coerção e desenvolvimento econômico nacional. No caso de Couto e Silva, estes objetivos, atrelados à ideia da segurança nacional e desenvolvimento, deveriam ser construídos em torno do medo da população perante as dificuldades passíveis de serem encontradas pelo país, da pobreza aos "inimigos políticos" do Estado: "O Estado soberano, surgido das fontes profundas do Medo para prover a segurança individual e coletiva 
na Terra, passaria a afirmar sua vontade onipotente sobre os destinos de todos os súditos que o haviam criado, assim mesmo, inigualável e autárquico". (COUTO E SILVA, 1981a, p. 7.).

A questão da defesa nacional e o compromisso coletivo da nação com o desenvolvimento do Estado nacional permanecem atuais, como é o caso também de um trabalho da Escola Superior de Guerra, de 2011, no qual estes argumentos são elencados e defendidos pelo Coronel Heleno Moreira: “Assim, fica bem claro a necessidade de disseminar e divulgar a importância da "defesa" na sociedade brasileira, mostrando que esse importante tema é de responsabilidade de todos os segmentos, de todas as expressões do poder nacional." Cabendo, ainda, resquícios do viés populista, resgatado dos anos anteriores da ditadura: "E que tudo isso será revertido para a população brasileira como um todo, seja de maneira negativa ou positiva, na denominada expressão psicossocial do poder nacional." (MOREIRA, 2011, p.101).

Ao seguir estes preceitos, não haveria brechas que permitissem o questionamento das ações governamentais, e assim, através do medo, garantia-se a segurança, integração e defesa do Estado nacional, pois este pensamento estaria sendo seguido pela retidão dos objetivos maiores da nação: “[...] pela própria necessidade de um raciocínio lógico, escorreito e severo, que o justificaria, de uma vez para sempre, contra todas as críticas e contra quaisquer argumentações." (COUTO E SILVA, 1981a, p. 7.). Caberia, portanto, ao cidadão, admitir sua insegurança para que, assim, a destinação de um novo e fortalecido Estado nacional brasileiro se firmasse. Nas palavras de Couto e Silva (1981a, p. 9),

\begin{abstract}
A insegurança do cidadão dentro de cada nação e a insegurança de uns Estados em face dos outros, a visão onipresente da guerra (...) dominam o mundo de nossos dias e explicam, por si sós, essa ânsia neurótica com que a Humanidade, enfim, se ergue e se lamenta e se debate, disposta até a escravizar-se a quaisquer senhores e a quaisquer tiranias, desde que the ofereçam, num prato de lentilhas, um pouco de segurança e de paz. E, assim, acaba ou acabará afinal por perder, com a Liberdade traída, a própria Segurança.
\end{abstract}

É interessante notarmos como esta responsabilidade individual, na visão do general, acaba por fundamentar sua noção coletiva sobre o nacionalismo: "Ser nacionalista é reconhecer, como suprema lealdade, a lealdade à nação de que é ínfima parte, mas parcela atuante e consciente." O indivíduo deveria estar pronto para sacrificar-se pelos objetivos da coletividade, simbolizada pelo Estado: "Ser nacionalista é estar sempre pronto a sacarificar qualquer doutrina, qualquer teoria, qualquer ideologia, sentimentos, paixões, ideais e valores, 
quando quer se evidenciem nocivos e de fato incompatíveis ante a lealdade suprema que se deve dedicar, sobretudo, à nação." (COUTO E SILVA, 1981a, p. 99).

Podemos resgatar as menções de Gramsci (2007) a respeito da relação entre o poderio político-militar e sua repressão ao povo que representa. $\mathrm{O}$ caso brasileiro é singular quanto a este cenário, assim como em outras ditaduras latino-americanas, pois o discurso encaixa-se perfeitamente ao argumento do filósofo italiano, quando este menciona a capacidade deste poder de repressão dispersar os movimentos dissidentes - os "inimigos" nomeados pelos generais teóricos do regime -, bem como de utilizar a integração do território para dar estofo retórico à sua ideologia nacionalista:

\begin{abstract}
A relação não é puramente militar, mas político-militar: com efeito, este tipo de opressão seria inexplicável sem o estado de desagregação social do povo oprimido e a passividade de sua maioria. Portanto, a independsncia não poderá ser alcançada com forças puramente militares, mas com forças militares e polítiõo-militares. De fato, se a nação oprimida, para iniciar a luta pela independência, tivesse de esperar a permissão do Estado hegemônico para organizar seu próprio exército no sentido estrito e técnico da palavra, teria de esperar bastante tempo (pode ocorrer que a reivindicação de ter um exérciro próprio seja concedida pela nação hegemônica, mas isto significa que uma grande parte da luta já foi travada e vencida no terreno politicomilitar). A nação oprimida, portanto, oporii inicialmente à força militar hegemônica uma força que é apenas "político-militar", isto é, oporá uma forma de ação política que tenha a virtude de determinar reflexos de caráter militar, no sentido de que: 1) seja capaz de desagregar intimamente a eficiência belica da nação hegemônica; 2) obrigue a força militar hegemônica a diluir-se e dispersar-se num grande território, anulando grande parte de sua eficiência bélica. (GRAMSCI, 2007, p. 43).
\end{abstract}

O Estado estaria no ponto mais alto de uma hierarquia de lealdade na qual o indivíduo está situado no ponto mais baixo, e à qual a população, em maior escala, deveria ser submetida: "Sem dúvida, o homem foi e sempre será o pólo de uma hierarquia de lealdades frequentes vezes, palco íntimo de dilaceradores conflitos entre lealdades diferentes." (COUTO E SILVA, 1981a, p. 96). Este pensamento pode ser constatado, por exemplo, em campanhas de publicidade governamental como a "Brasil, ame-o ou deixe-o".

Em suma, há proposições calcadas em termos como lealdade, facções (para os grupos contrários ao regime), supremacia e valores ideais, as quais são utilizadas para dar o tom de severidade em torno não apenas das teorizações de Couto e Silva (1981a), mas presente nos anos de maior rigidez da ditadura militar sobre a população brasileira: 
Ser nacionalista é reconhecer, como suprema lealdade, a lealdade à nação de que se é ínfima parte, mas parcela atuante e consciente. Ser nacionalista é sobrepor, portanto, a quaisquer interesses outros, individuais ou de facções ou de grupos, a quaisquer vantagens regionalistas ou paroquiais, os verdadeiros interesses da nacionalidade. Ser nacionalista é estar sempre pronto a sacrificar qualquer doutrina, qualquer teoria, qualquer ideologia, sentimentos, paixões, ideais e valores, quando quer se evidenciem nocivos e de fato incompatíveis ante a lealdade suprema que se deve dedicar, sobretudo, à Nação (COUTO E SILVA, 1981a, p. 99).

Esta concepção ajustava-se de forma imediata e direta com a ideia de Estado não apenas de Couto e Silva, diga-se de passagem, mas de todo o corpo político vigente na ditadura militar, no qual o território como corpo do Estado ganha projeções jamais vistas na história recente do Brasil: "[...] um organismo político com existência real sobre uma dada área e em um momento dado", e aqui temos a posição em relação à coesão dos poderes sobre as possíveis iniciativas contrárias a eles, situação vivida nas duas décadas de dominância do regime na política nacional: “[...] nada mais traduz que uma preponderância das forças coesivas políticas, econômicas etc., sobre as forças desagregadoras de toda espécie (ou, pelo menos, um equilíbrio mais ou menos estável entre essas forças opostas)" (COUTO E SILVA, 1981a, p. 211).

Num ponto mais surpreendente, pela franqueza e objetividade, há o entendimento do poder estatal como promotor, e ente responsável por garantir os objetivos nacionais pelas vias e meios que lhe fossem necessários: "[...] a vida do Estado é multiforme, estendendo-se lhe a ação promotora, controladora e inibitória ou coercitiva a campos vários e múltiplos setores, todos interdependentes" (COUTO E SILVA, 1981a, p. 15). E a ufania, política e telúrica, logicamente, estava presentes nesta formulação de Couto e Silva (1981a, p. 169): “[...] como entidade internacional dotada de um poder soberano, como organismo social em processo de integração continuada, como nação próspera e prestigiada no mundo". Oe entendimento do Estado como fomentador e articulador da ordem, pode ser observado no organograma sintético elaborado pelo próprio general: 
Figura 1 - A Segurança Nacional

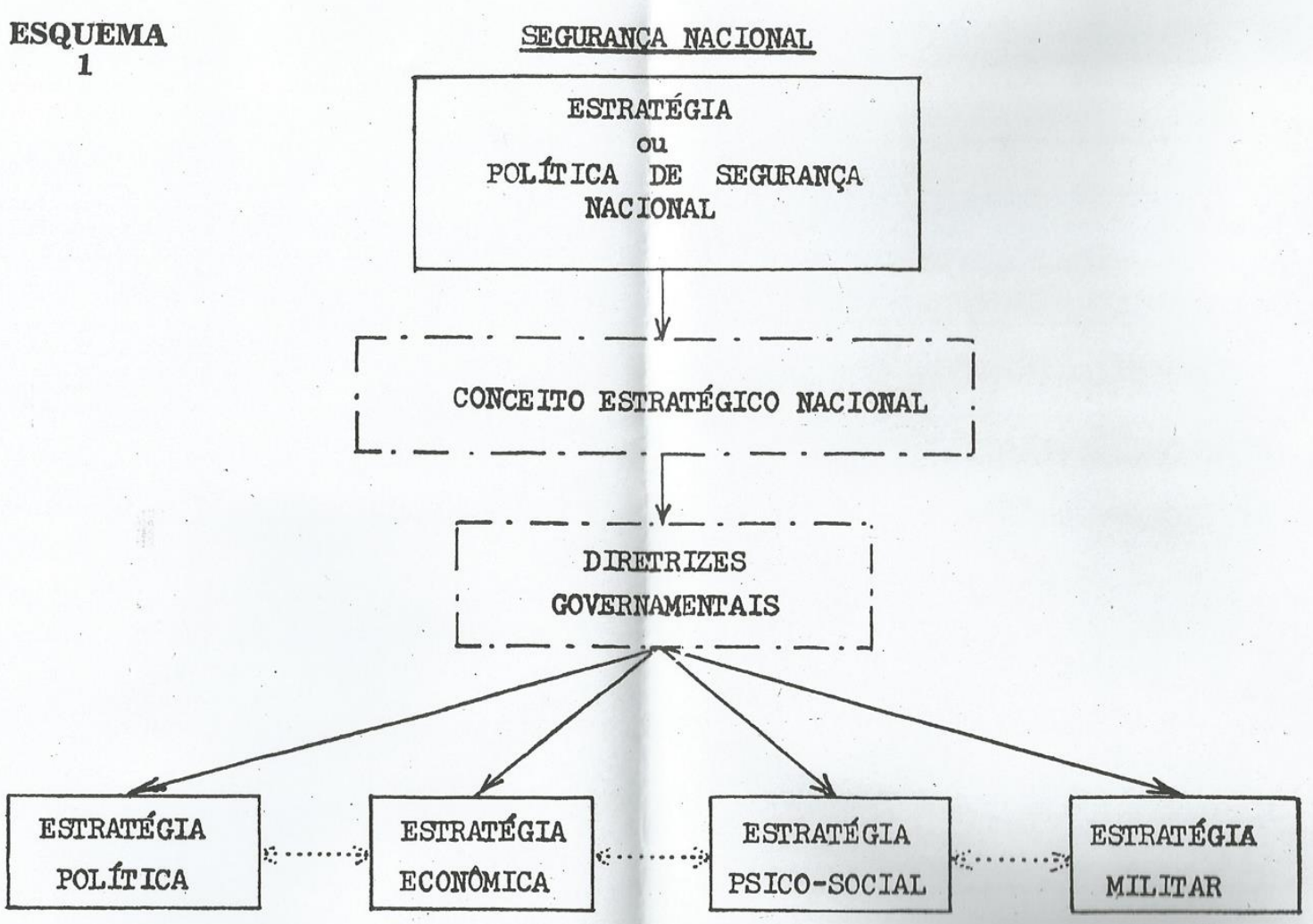

Fonte: COUTO E SILVA, 1981a, p. 26

Podemos deixar ao próprio Couto e Silva (1981a) a tarefa de explanar sobre tal organização do Estado: “Temos, assim, na cúpula da Segurança Nacional, uma Estratégia, por muitos denominada Grande Estratégia ou Estratégia Geral, arte da competência exclusiva do governo e que coordena, dentro de um Conceito Estratégico fundamental.” Em outras palavras, aqui se verifica a preocupação com todas as esferas do Estado nacional nas quais o poder político rijo e reto deveria se pautar: “[...] todas as atividades políticas, econômicas, psicossociais e militares que visam concorrentemente à consecução dos Objetivos nos quais se consubstanciam as aspirações nacionais de unidade, de segurança e de prosperidade crescente." (COUTO E SILVA, 1981a, p. 25). Esta Grande Estratégia teria como objetivo último o desenvolvimento nacional, o futuro progressista e moderno tão almejado pelas lideranças políticas brasileiras desde a República da Espada pré-Estado Novo:

No quadro de uma Política toda inclusiva, visando ao engrandecimento da nação e ao bem-estar e prosperidade do povo em seu conjunto, a Estratégia se restringe ao domínio específico menor da segurança nacional e, aí, o bemestar e a prosperidade, como objetivos a alcançar, encontram guarida, apenas na medida em que interessam, com elevado grau de prioridade, ao 
fortalecimento do Potencial Nacional, em particular ao enrijecimento do próprio moral da população. (COUTO E SILVA, 1981a, p. 102).

Mais adiante, daremos maior visibilidade à junção entre a ideia de estratégia e a inserção, inevitável e inerente, do espaço neste debate. Por ora, voltemos a atenção a outro general que engendrou os pilares da política militar da ditadura: Meira Mattos. Em suas teorizações sobre o poder do Estado, há a influência da destinação norte-americana manifesta e, de igual modo, a preocupação com a coesão nacional como símbolo máximo do poderio político do governo: "A coesão nacional é um fator inseparável da liderança. Sem essa liderança, as maiorias e minorias nacionais se perderão nos desvãos sectários da polêmica estéril e a nação se desencontrará de seu destino. Sem liderança não haverá objetivo, não haverá convergência, não poderá haver força, potência.” (MATTOS, 1975, p. 72).

Esta coesão não é apenas política ou territorial, pois fundamenta toda a ideia de lealdade nacional que permeava a ditadura militar; o território coeso deveria estar assentado na união de seu povo, pelos meios necessários que estivessem à disposição do Estado: "Sem dúvida, o homem foi e sempre será o pólo de uma hierarquia de lealdades - frequentes vezes, palco íntimo de dilaceradores conflitos entre lealdades diferentes." (COUTO E SILVA, 1981b, p. 96). Pensamento este que será visto, por exemplo, em campanhas de publicidade governamental como a "Brasil, ame-o ou deixe-o".

O orgulho telúrico e a ufania edênica colaboraram para a afirmação do discurso da coesão nacional - social e espacial - do Brasil, e foram amplamente utilizados nos governos militares para estes fins: "[...] a terra (meio físico) sempre teve uma influência muito grande no destino do home, assim como o país no dos povos e, juridicamente falando, o território no destino dos Estados.” De certa forma, a utilização das riquezas naturais se tornaria inevitável; os militares não só o fizeram como a potencializaram a nível de ideologia espacial em todas as esferas do poder político: "Essa influência se traduz através de vários fatores, entre os quais se destacam como principais, a forma, a extensão, a posição a altitude, o clima e a cobertura vegetal [...] No palco da eterna luta entre o homem e o meio ambiente entrechocam-se as qualidades do homem e as condicionantes da terra. (MATTOS, 1975, p. 7).

Se Couto e Silva fazia uso de uma linguagem mais objetiva e diretiva, Meira Mattos (1975) não se priva em trazer simbologias edênicas para a defesa de suas teorias geopolíticas e estratégias, ambas revestidas como a luta do homem contra o meio, a fim de garantir o curso da civilização em direção ao progresso: “A façanha humana no planeta é marcada pela luta. Venceram os fortes no confronto com o meio físico e na defrontação com as dificuldades para 
ARAÚJO, G. C. C.

harmonizar a seu favor o ambiente humano." Assim, estaria construído o caminho para o almejado progresso brasileiro: "O homem, o grande autor no cenário das civilizações, venceu quando teve qualidades intrínsecas, de caráter e de vontade, para se deixar influenciar pelos estímulos do meio.” (MATTOS, 1975, p. 8-9). Em palavras paralelas, Couto e Silva elenca seus Objetivos Nacionais Permanentes, também vinculados à "vontade" coletiva, estruturados pela defesa e segurança nacionais, e à lealdade do povo que

[...] não se traduz apenas no patriotismo - um mero sentimento, nobre e alevantado e inspirador, embora - mas no nacionalismo que é muito mais do que isso, porque é, sobretudo, uma vontade: vontade coletiva, vontade consciente, vontade criadora de engrandecer cada vez mais a nação, realizando plenamente e, sempre que necessário, salvaguardando a qualquer preço os Objetivos Nacionais Permanentes. Sobrevivência da nação como grupo integrado, em prosperidade e crescente bem-estar - autodeterminação ou soberania, integração social, prosperidade e prestígio - eis aí, pois, o núcleo fundamental em torno do qual o nacionalismo se condensa e cristaliza. (COUTO E SILVA, 1981b, p. 98).

E como não poderia deixar de ser, a influência desta visão dos generais perduraria até os dias atuais, principalmente na Escola Superior de Guerra. Assim, podemos, novamente, aferir esta continuidade de pensamento sobre a ufania edênica como recurso ideológico para a proteção, unidade, desenvolvimento e integração nacional, pelo coronel Heleno Moreira:

Brasil está prestes a entrar em guerra? O Brasil tem algum inimigo declarado? Com certeza, a resposta será negativa. Em um cenário de curto e médio prazo, repetem-se as perguntas anteriores. E num cenário de longo prazo? Acredita-se que as respostas continuarão negativas. Então, para que se preocupar com mobilização nacional, se há outras medidas bem mais importantes e necessárias a serem providenciadas? O Brasil é um país de dimensões continentais que ocupa uma área de $8.514 .876,599 \mathrm{~km}^{2}(47 \%$ da América do Sul) e possui inúmeras riquezas. Pode-se destacar a Amazônia, com sua fauna, flora, biodiversidade, recursos minerais, além de possuir o maior banco genético do planeta. O Brasil é banhado pelo oceano Atlântico, também denominado Amazônia Azul, com suas riquezas incomensuráveis, sendo que o chamado pré-sal está hoje em evidência. Cerca de $95 \%$ das trocas comerciais brasileiras são realizadas pelo oceano Atlântico. Existe muita água doce no país. Há inúmeros rios, além dos aquíferos Alter do Chão e Guarani. Dizem alguns analistas que a água doce será causa de guerras no futuro. A população mundial está crescendo e, com isso, necessita-se cada vez mais de alimentos. O Brasil possui bastante área agricultável, em condições de atender às demandas, a cada vez que os países vão se desenvolvendo e necessitando, consequentemente, de mais alimentos para seus habitantes. E também muita energia considerada limpa: muita água, muito sol, muitos ventos. Acredita-se que esses motivos já justificam essa necessidade de se preocupar com mobilização, uma vez que o país está 
ARAÚJO, G. C. C.

em pleno desenvolvimento, com objetivos claros de chegar ao patamar do Primeiro Mundo. (MOREIRA, 2011, p. 99).

Todos estes aspectos visíveis nas teorizações do generais Meira Mattos e Couto e Silva, como o patriotismo nacionalista, a ufania edênica, o papel provedor da ordem do Estado, a questão da segurança e defesa nacionais, a integração e coesão do povo e território, e a modernização do país como caminho para o progresso fazem parte do pensamento geopolítico do período ditatorial de nossa história.

Tanto por parte dos políticos e militares, como também por parte de pensadores, em especial da Geografia, é possível verificar a formulação de conceitos, noções e proposições a respeito do papel central do espaço geográfico na organização e estruturação do poder estatal perante sua nação. Explorar mais a fundo estas infiltrações das ideologias militares no pensamento geográfico e geopolítico é de fundamental importância para a compreensão mais ampla da complexidade de todo o contexto da ditadura militar no Brasil.

\section{CONSIDERAÇÕES FINAIS}

O tema da segurança e integração nacional é profícuo e denso, com diversificadas aberturas de aprofundamento, seja pela economia ou história, pela ciência política ou temas de proximidade geográfica, como foi o caso do presente texto. Em relação ao Brasil, há um considerável histórico de preocupações a respeito da integração nacional, permeadas pelas questões de segurança territorial, abrangendo diferentes momentos da formação territorial do país, ao mesmo tempo em que é possível encontrar estes traços na objetividade do espaço geográfico brasileiro.

Espera-se, com este artigo, suscitar a discussão entorno da Geopolítica premente ao longo do desenvolvimento apresentado até aqui. Em nosso caso, ainda há a especificidade da presença de um período claro de controle das instituições públicas por uma junta militar, dando maiores e mais complexos elementos de análise para este debate. A partir destas observações é que coloca-se em pauta as grandes possibilidades de expansão do tema, para assim melhor compreender a formação histórica do território brasileiro, tendo como base, especialmente, a política, a economia, a história e a infiltração destas na ciência geográfica, formando um constructo analítico-metodológico capaz de abarcar as diferentes facetas seja da integração como da segurança nacional. 


\section{Referências Bibliográficas}

BRASIL. Decreto-Lei $n^{o}$ 314, de 13 de Março de 1967. In: < http://www2.camara.leg.br/legin/fed/declei/1960-1969/decreto-lei-314-13-marco-1967366980-publicacaooriginal-1-pe.html>. Acesso: 20.01.2016.

BRASIL, Emenda Constitucional $n^{\circ} 1$ de 17 de outubro de 1969 In: < http://www.planalto.gov.br/ccivil_03/Constituicao/Emendas/Emc_anterior1988/emc0169.htm> Acesso: 20.01.2016.

COUTO E SILVA, Golbery. Planejamento estratégico. Rio de Janeiro, José Olympio, 1981a. Conjuntura política nacional: o poder executivo \& Geopolítica do Brasil. Rio de Janeiro, José Olympio, 1981b.

FIGUEIREDO, João. Discurso de Posse. 15 de março. 1979. Brasília, Palácio do Planalto. In: $<\quad$ http://www.biblioteca.presidencia.gov.br/ex-presidentes/jb-figueiredo/discursos-deposse/discurso-de-posse/view> Acesso: 20.10.2015.

Discurso à Nação Brasileira Por Ocasião Do $20^{\circ}$ Aniversário da

Revolução. 31 de março. 1984. Brasília, Palácio do Planalto. In: <http://www.biblioteca.presidencia.gov.br/ex-presidentes/jb-figueiredo/discursos1/1984/13.pdf/at_download/file> Acesso: 20.10.2015

GIANNASI, Carlos Alberto. A Doutrina de Segurança Nacional E O Milagre Econômico. Tese de Doutorado em História Econômica. Universidade de São Paulo. São Paulo: USP, 2011.

GEISEL, Ernesto. Discurso feito aos dirigentes da Arena, no Palácio da Alvorada (1974) Disponível em $\quad$ http://www.biblioteca.presidencia.gov.br/ex-presidentes/ernestogeisel/discursos-1/1974/17.pdf/download $>$ Acesso. 10.10.2015.

GRAMSCI, Antonio. Cadernos do cárcere, volume 3. Trad. Carlos Nelson Coutinho. Rio de Janeiro: Civilização Brasileira, 2007.

MATTOS, Meira, Brasil: Geopolítica e Destino. Rio de Janeiro: Editora Biblioteca do Exército, 1975.

MÉDICI, Emílio Garrastazu, $O$ Jogo da Verdade (1969). In: http://www.biblioteca.presidencia.gov.br/ex-presidentes/emilio-medici/discursos/1969/01.pdf/view Acesso: 10.11.2015.

MORAES, Antonio Carlos Robert. Território e Identidade na Formação Brasileira. In: Ideologias geográficas. 5. ed. São Paulo: Annablume, 2005.

MOREIRA, Heleno. Mobilização nacional para que? In: Revista da Escola Superior de Guerra, v. 26, n. 53, p. 98-107, jul./dez. 2011. 
ARAÚJO, G. C. C.

REZENDE, Maria José de. A ditadura militar no Brasil: repressão e pretensão de legitimidade : 1964-1984. Londrina : Eduel, 2013.

VLACH, Vânia Rubia Farias. Estudo preliminar acerca dos geopolíticos militares brasileiros. In: Terra Brasilis [Online], 4 - 5 | 2003. p. 1-13. 